\title{
El corral de comedias de Cartagena en el siglo XVII: nuevos documentos
}

\section{The corral de comedias of Cartagena in the 17th century: New Documents}

\section{Rafael Sánchez Martínez}

http://orcid.org/0000-0003-0209-6926

Universidad de Murcia

ESPAÑA

rafaelsm@um.es

[Hipogrifo, (issn: 2328-1308), 9.1, 2021, pp. 1285-1303]

Recibido: 30-09-2020 / Aceptado: 22-10-2020

DOI: http://dx.doi.org/10.13035/H.2021.09.01.69

Resumen. La construcción de edificios teatrales en España en el Siglo de Oro tuvo un fuerte auge en los primeros años del siglo XVII. La ciudad portuaria de Cartagena (España) contó con un gran corral de comedias a partir de 1614. Situado en la parte noble de la ciudad, contó con todos los elementos propios de los teatros barrocos. Un edificio realizado expresamente para representar teatro que fue propiedad del ayuntamiento e impulsó vivamente el arte escénico en Cartagena. Un corral de comedias que compartió características arquitectónicas con otros teatros del sureste español. Con esta casa de comedias la ciudad de Cartagena quedó inserta dentro del panorama teatral del siglo XVII. Con documentación archivística de la época, casi toda inédita, este artículo pretende situar el lugar que ocupó este teatro en la ciudad, hacer una reconstrucción documental del edificio y señalar la importancia de la representación teatral en la Cartagena barroca.

Palabras clave. Cartagena; corral de comedias; siglo XVII; teatro.

Abstract. The construction of theatrical buildings during the Spanish Golden Age boomed in the early 17 th century. In the port city of Cartagena (Spain) there was a large corral de comedias, courtyard theatre, from 1614 onwards. Located in the noble quarter of the city, the theatre boasted all the elements that baroque buildings used to have and shared some architectural features with other theatres in the southeast of Spain. The building was owned by the City Hall and was specifically built to perform plays, which helped boost the Performing Arts in Cartagena. 
Thanks to this theatrical building, the city of Cartagena fully entered the theatrical life of the 17th century. By presenting archivist documents from the period, mostly unpublished, this article aims to locate the place where this courtyard building stood, to present a documentary recreation of the building, and to point out the importance of stage productions in Cartagena throughout the Baroque period.

Keywords. Cartagena; corral de comedias; 17th century; Theatre.

El paisaje urbano de una mediana o gran ciudad en los primeros años del siglo XVII ya contaba con un corral o casa de comedias para representar obras de teatro. En la actual capital de la Región de Murcia se construyó el teatro del Toro en 1609, aunque desde 1593 ya se realizaban representaciones teatrales en el patio del hospital de Nuestra Señora de Gracia y Buen Suceso'. Pero Murcia no fue la única ciudad de esta región que contó con un corral de comedias en los primeros años del seiscientos. En 1614 se empezó a construir una casa de comedias en la ciudad de Cartagena, que por su situación geográfica y por contar con uno de los puertos marítimos más importantes de la Corona Hispánica llegó a ser una ciudad principal en la primera mitad del siglo XVII, por ejemplo, en el año 1620 contaba con 10.000 habitantes $^{2}$. Hasta la segunda mitad de la centuria del seiscientos vivió un auge económico y social que la convirtió en una de las principales ciudades del Mediterráneo ${ }^{3}$. En este contexto socioeconómico se edificó el primer teatro comercial de esta ciudad. Para realizar con detalle el presente estudio sobre la citada casa de comedias cartagenera, extraigo la información (la mayoría inédita) de documentación del siglo XVII procedente, en su mayor parte, del Archivo Municipal de Cartagena (AMC), cuya transcripción ${ }^{4}$ forma parte de este presente ensayo ${ }^{5}$.

Así pues, como indica un fragmento del acta del capítulo que celebró el ayuntamiento el 12 de agosto de 16146, anteriormente a la construcción del corral de comedias se realizaban las representaciones teatrales en la Casa del Rey. Este edificio, que ocupaba un lugar céntrico en la ciudad, se usaba como armería, almacén de munición y lugar de descanso para las tropas reales. El enclave que se utilizaba para hacer teatro hasta 1614 (la Casa del Rey) no era un lugar adecuado para la actividad teatral, porque las representaciones de comedias provocaban muchos problemas ${ }^{7}$. De tal manera que, Cartagena necesitaba un lugar exclusivo donde se pudiera practicar la actividad teatral que tanto empuje estaba teniendo en los pri-

1. Ver Sánchez Martínez, 2009.

2. Montojo Montojo, 1993, p. 24

3. Velasco Hernández, 2005, p. 494.

4. En la transcripción del documento 1 he eliminado el seseo que aparece en algunas palabras para una mejor comprensión del texto.

5. Este artículo va acompañado de una serie de imágenes que debo a la inestimable ayuda de Sergio Mayor del Amor.

6. AMC, Acta Capitular, 12/8/1614. Documento transcrito también en Tornel, Grandal y Rivas, 1985, p. 63. 7. «Frecuentan esta ciudad muchas compañías de comediantes, las cuales hasta ahora han representado en la casa real de municiones de Su Majestad, y porque se ha entendido que su Majestad tiene mandado no se represente en la dicha casa por algunos inconvenientes a su real servicio, y por excusar 
meros años del siglo XVII. De esta manera, en el cabildo municipal de 20 de noviembre de $1614^{8}$ se acordó definitivamente la construcción de una casa de comedias para esta ciudad.

Ya en el acta capitular de 12 de agosto de 1614, se hace alusión a un espacio en la calle Bodegones: «tome el sitio que es de los hermanos de Francisco Graso, difunto, que está entre la calle del hospital de Señora Santa Ana y la calle de los bodegones», como probable ubicación del corral de comedias. En la sesión del cabildo de la ciudad de 20 de noviembre de 1614, se confirma dicho lugar como emplazamiento de este nuevo teatro. Se trataba de un espacio entre la calle Bodegones y la calle Mayor, que lindaba con una de las construcciones más señeras de la ciudad: el hospital de Nuestra Señora de Santa Ana. El hecho de que se construyera al lado del postigo del citado hospital y que en la documentación se cite el nombre de la calle - que se conserva en la actualidad: Bodegones- hace que podamos establecer actualmente con exactitud el lugar donde se levantó la casa de comedias. El hospital de Santa Ana tiene un origen tardomedieval y se encontraba en un lugar céntrico $0^{9}$ : detrás del ayuntamiento, cerca de la plaza Mayor y con fachadas a la calle Bodegones y a la calle Mayor, y tuvo una gran relevancia durante todo el siglo XVII. Pero además, el lugar elegido para construir el corral de comedias, al lado del hospital, era parte del centro neurálgico de la ciudad ${ }^{10}$ no solo por su centrismo urbano, sino porque además, la calle Bodegones servía de lonja y lugar comercial de primer nivel en la ciudad ${ }^{11}$. La ubicación del teatro en un lugar de gran vida comercial es lo que provoca que cuando se está proyectando la construcción del corral de comedias, también se idee la construcción de un peso real al lado del teatro para vender cinta de carne ${ }^{12}$.

El solar elegido para la construcción del corral de comedias fue el que ocupaban unas casas cuyo propietario se llamaba Francisco Grasso. Se aprovechó que se habían derribado parte de dichas viviendas para construir en este sitio. Pero como no era suficiente espacio para la construcción que el ayuntamiento tenía en mente, se acuerda comprar más inmuebles. Así pues, se adquiere una casa a Lucas Maldonado a través de Andrés González, ya que Maldonado vivía en Madrid. Dicha vivienda era medianera con las posesiones de Grasso. La construcción de la casa de comedias fue una empresa en la que el ayuntamiento invirtió mucho dinero y tomó como algo prioritario. Desde el primer momento la inversión, construcción y gestión del corral de comedias fue municipal, solo a partir de 1693 se comparte dicha explotación con los hermanos de San Juan de Dios, que también se encargaban del Hospital de Santa Ana. No obstante, en los años de la construcción de la casa de comedias la titularidad fue totalmente del Ayuntamiento de Cartagena. En la sesión capitular de 20 de noviembre de 1614 se nombran a los regidores Juan

alguna diferencia y encuentros que ha habido entre la justicia ordinaria de esta ciudad y el proveedor de Armadas de Su Majestad» (AMC, Acta Capitular, 12/8/1614).

8. AMC, Acta Capitular, 20/11/1614.

9. Ver Ferrándiz Araujo, 2006.

10. Pérez Yelo, 2013, p. 40

11. Andrés Sarasa, 1981, p. 14

12. AMC, Acta Capitular, 20/11/1614

HIPOGRIFO, 9.1, 2021 (pp. 1285-1303) 
González de Sepúlveda y Jacomo Corbari como los comisarios encargados por parte del ayuntamiento de la construcción de dicha casa de comedias. A estos se les otorga poder a través de carta notarial ${ }^{13}$ para que tomen las decisiones necesarias respecto a la construcción del nuevo teatro, disponiendo del dinero necesario de los propios y mayordomos del ayuntamiento. Aunque la creación de un teatro también suponía un aprovechamiento económico para la ciudad, ya que este se convertía en un propio de la misma y por medio de su arrendamiento o explotación revertían en el ayuntamiento pingües beneficios. Además, en el caso de Cartagena, en 1614 se ponían en marcha dos fuentes de negocio a la vez: la casa de comedias y el peso real. Este proyecto fue acogido positivamente en el seno del cabildo de la ciudad de forma mayoritaria. De tal manera que la puesta en marcha de la construcción de la obra de la casa de comedias fue inmediata a su aprobación en la sesión capitular de 20 de noviembre de 1614. Ya el 23 de noviembre de $1614^{14}$ tres maestros de albañilería de la ciudad hacen postura para realizar las tapias y paredes del nuevo teatro, y se le concedió el contrato a Juan Imbernón por cuatro reales y medio cada tapia.

La memoria constructiva del corral de comedias de Cartagena de 1614, documento $1^{15}$, nos aporta valiosísima información. Se trata de una memoria con detalles y medidas exactas de las partes de la casa de comedias: una descripción de la fábrica del teatro que realiza el maestro de obras al alcalde mayor de la ciudad. Por lo tanto, a través de esta documentación ${ }^{16}$ podemos, por primera vez, hacer una fiel reconstrucción del primer teatro comercial de la ciudad de Cartagena y de un ejemplo de una casa de comedias de principios del siglo XVII. Las medidas de longitud están expresadas en varas, palmos y pies. Todas las medidas en el reino de Murcia en el siglo XVII siguen la regularización que estableció en 1568 Felipe II para el reino de Castilla. De tal manera que una vara equivale a $0,835 \mathrm{~m}$, un pie a $0,278 \mathrm{~m}$ y un palmo a $0,208 \mathrm{~m}^{17}$.

Una primera idea que se desprende del análisis del documento 1 es que el teatro cartagenero de 1614 fue un edificio de nueva planta, que arranca desde su inicio como un inmueble nuevo en el solar que habían dejado las casas de Grasso y Maldonado, una creación ex profeso para albergar representaciones teatrales sin aprovechar partes de otras viviendas o edificaciones colindantes con el teatro, más allá de la pared medianera entre el teatro y el hospital de Santa Ana. Este edificio se construyó durante la ola de edificación de teatros que se dio en parte del territorio español en el primer cuarto del siglo XVII. A finales del siglo XVI, en un primer ciclo constructivo, se crearon en las ciudades más importantes teatros utilizando edificaciones ya existentes como patios interiores o patios de hospital. Así surgieron en

\footnotetext{
13. AMC, Acta Capitular, 2/12/1614.

14. AMC, CH02290, Documento 2.

15. AMC, CH02290, Documento 1

16. El documento 1 está plagado de deterioros, que en la transcripción resuelvo cuando falta texto con la siguiente indicación: [...]

17. Ver Basas Fernández, 1980.
}

HIPOGRIFO, 9.1, 2021 (pp. 1285-1303) 
Madrid el corral del Príncipe y de la $\mathrm{Cruz}^{18}$ o en Sevilla el corral de las Atarazanas ${ }^{19}$. Sin embargo, en los primeros años del siglo XVII la mayoría de construcciones teatrales no se limitaban a aprovechar espacios comunes ya preexistentes, sino que eran edificaciones de nueva planta, como el teatro de Córdoba ${ }^{20}$ de 1602, el teatro del Toro de Murcia de 160921, la nueva casa de comedias de la Olivera de Valencia, inaugurada en 1619 aunque se empieza a remodelar en $1618^{22}$ o el corral de la Montería de Sevilla de $1626^{23}$. Inmuebles, todos estos, que se construyeron solo con la idea de servir como espacio de representación. Así pues, en esta última serie se debe incluir el teatro de la ciudad de Cartagena de 1614. Esta casa de comedias fue una construcción de tres pisos - planta baja y dos cuerpos más-, que alternó distintos materiales: madera, piedra y ladrillo. Un edificio que contuvo las partes habituales de un teatro barroco: aposentos, vestuarios, tablado, cazuela, balcones y escaleras de acceso. En las siguientes líneas haré un análisis pormenorizado de cada una de dichas partes con la información extraída de la memoria constructiva de la casa de comedias de Cartagena de 1614 (documento 1), con el fin de presentar una reconstrucción documental detallada.

En el citado documento 1 se hace referencia a una importante intervención en las paredes maestras del teatro, reforzándolas y convirtiéndolas en fuertes construcciones, asegurando así la fábrica de la mejor manera. La planta del teatro de comedias medía 360,45 m2 ya que tuvo de largo 19,622 m y 18,37 m de ancho. Estas medidas hacen que la casa de comedias fuera de un tamaño considerable, por ejemplo, la planta del teatro del Príncipe medía $340 \mathrm{~m} 2$ y la de la nueva casa de la Olivera 24 395,29 m2. En el documento 1 cuando se hace alusión a los tejados se lee literalmente: «Y todos los dichos tejados serán hechos de teja [...] conformidad todo el corral en redondo». Además, cuando se describe en el mismo documento la construcción de los aposentos y su ubicación se especifica que: «se puedan andar a la redonda». Estos testimonios indican que la planta del corral cartagenero tenía forma semicircular. Este modelo de planta (Imagen 1) entronca con la planta semicircular del teatro de Murcia que se edificó en 160925. Se ha de indicar que a su vez el modelo murciano fue una copia ${ }^{26}$ de la que existía en el teatro de Córdoba ${ }^{27}$. Así pues, el teatro del Toro de Murcia sirvió como modelo para la casa de comedias de Cartagena de 1614 -en el propio documento 1 hay referencias directas al teatro murciano, cuando se detallan las dimensiones del tablado-. Por todo esto el teatro cartagenero comparte fisonomía no solo con la casa de comedias de Murcia (1609), sino con la de Córdoba (1602) y en cierta manera con teatros posteriores,

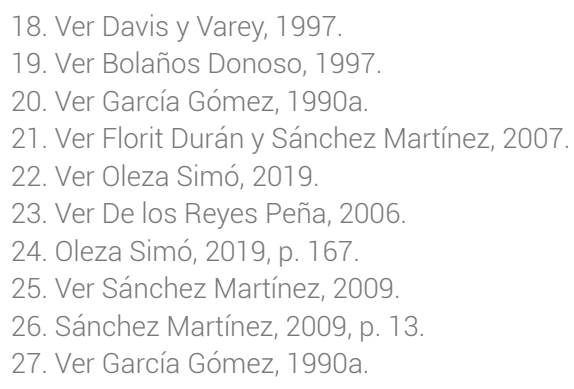


como la nueva casa de la Olivera de Valencia (1618) -que daba apariencia semicircular aunque realmente su planta tenía forma de polígono ochavado- y de alguna forma también -aunque no era una planta semicircular sino oval-con el corral de la Montería de Sevilla (1626). La elección de este tipo de planta es porque ayuda a una mejor visión del escenario y a una mejor propagación de la voz desde el mismo hasta los espectadores, como ya indicaba Vitrubio en sus escritos sobre arquitectura ${ }^{28}$.

En el interior del teatro se construyeron dieciocho pilares ochavados de ladriIlo grueso. Esta hilera semicircular de pilares distaba desde las paredes maestras $3,75 \mathrm{~m}$. Los citados dieciocho pilares fueron la sujeción de dos cuerpos - primer y segundo piso- en los que se situaron los aposentos, cazuela, balcón de la ciudad y vestuarios, aunque la documentación se refiere a ellos como «cuerpo alto y bajo» 0 «primero y segundo cuerpo de aposentos». Entre el suelo del teatro y el primer piso existía una distancia de 2,5 m de altura. Este primer piso (Imagen 2), que descansaba en los pilares de ladrillos, estaba constituido por cuartones de madera de $4,16 \times 3,75 \mathrm{~m}$. Dichos maderos se asentaban en vigas y jácenas de madera que se apoyaban en los citados pilares, y además estaban enclavados en las paredes maestras -que como ya hemos indicado se construyeron y reforzaron a conciencia-. También el suelo del primer piso se reforzó con ripias de madera más pequeñas que los cuartones. Desde este citado primer piso nacían dieciocho pilares, pero de madera, en el mismo lugar que los pilares de ladrillo, para sujetar un segundo piso (Imagen 3). Tanto el primer piso como el segundo tuvieron la misma altura: 2,1 m. El suelo de este segundo piso también era de madera y la confección del mismo fue igual que la del primero: con un trazado de vigas y jácenas de madera, y cuartones y ripias encima. Aunque la documentación no lo detalla -el deterioro del documento lo impide leer-, se entiende que desde el segundo cuerpo de la misma manera nacería un juego de pilares de madera que sujetarían el tejado al que alude el documento 1. Todo el tejado del teatro estaba a la misma altura y compuesto por el mismo tipo de teja.

El acceso a todos estos lugares se hacía desde la calle por distintas escaleras y entradas, que desarrollaré en líneas posteriores. Para entrar a las citadas dependencias en el primer y segundo piso, se hacía desde un pasillo común a todas, que circundaba todo el teatro con una anchura de 1,05 m. Un corredor interno que servía de distribuidor de cada una de las estancias en ambos cuerpos. La casa de comedias de Cartagena tenía veintidós aposentos repartidos tanto en el primero como en el segundo piso (Imágenes 2 y 3). Dichos aposentos eran habitaciones de 2,22 $\mathrm{m}$ de ancho, 2,1 $\mathrm{m}$ de alto y 2,7 $\mathrm{m}$ de profundidad, aproximadamente $6 \mathrm{~m} 2$ (Imagen 4). Estos habitáculos estaban separados unos de otros por un fino tabique de ladrillo revestido de yeso. Además, todos los aposentos contaban con una puerta que daba al citado pasillo. Los aposentos estaban orientados de la mejor forma para obtener una buena visión del escenario, como dice literalmente el documento 1. Los veintidós aposentos del teatro barroco cartagenero coinciden con el número 
de aposentos que tenía el Corral de la Cruz de Madrid ${ }^{29}$ y casi se ajusta a los que existieron cuatro años después en la nueva casa de la Olivera: veinte ${ }^{30}$. Así pues, se trata de un número importante que estaba en consonancia con los grandes teatros de su época. Otro espacio existente en los cuerpos elevados de la casa de comedias fue el balcón de la ciudad. Este era un espacio que existía en todos los teatros barrocos, que estaba destinado a las autoridades civiles y en muchas ocasiones a las eclesiásticas. En el teatro de Cartagena de 1614 se situó en el primer cuerpo, era independiente de los aposentos pero alineado con ellos. Sus medidas eran de 2,1 m de alto, 2,7 m de profundidad pero de largo tenía 5,2 m (Imagen 6). Como se puede observar, se trataría de una estancia el doble de amplia que un aposento normal. Dicho balcón se situó en el mejor sitio del corral para obtener una óptima visión del escenario y para que los demás asistentes al teatro también pudieran ver con claridad quién ocupaba este puesto tan principal.

La cazuela para las mujeres fue la parte del teatro más amplia donde podía acudir público y, según el documento 1, ocupaba toda la fachada. Un balcón corrido, que ocupaba toda la parte frontal, respecto al escenario, del segundo piso de la casa de comedias. Aunque la documentación no lo sitúa exactamente en dicho cuerpo del teatro, es lógico pensar que en la parte justo enfrente del escenario en el primer piso se situara el balcón de la ciudad, como ya hemos indicado, y en el piso superior la cazuela para las mujeres (Imagen 6). De la misma forma podemos colegir que las medidas de altura y de profundidad coincidirían con las de los aposentos ya que formaban un mismo cuerpo constructivo: 2,1 $\mathrm{m}$ de alto, por 2,7 $\mathrm{m}$ de fondo y aproximadamente $18 \mathrm{~m}$ de ancho ya que esta es la medida del ancho de la planta del corral de comedias - por lo tanto la medida aproximada de la fachada-. Además, en la cazuela se instalaron gradas de ripias de madera para asiento de las mujeres. Estas gradas fueron de poco peso para evitar posibles derrumbes en esta parte del corral (Imágenes 3 y 6 ).

El teatro barroco cartagenero contó con dos vestuarios, uno para hombres y otro para mujeres. Se ubicaron cada uno de ellos a la misma altura que los aposentos altos y bajos (es decir, en el primer y segundo piso). Esto supuso una novedad respecto a otros teatros barrocos, ya que lo habitual era que se situaran debajo del tablado - como en el teatro del Toro de Murcia ${ }^{31}$ y en los corrales madrileños ${ }^{32}$-, o aledaños al escenario - como en Córdoba ${ }^{33}$ y en el corral de la Montería ${ }^{34}-$. La altura de los vestuarios fue de 2,1 m ya que ocupaban la misma línea que los aposentos, cazuela y balcón de la ciudad en sendos pisos. El fondo de dichos vestuarios era de 3,75 m (Imagen 5). Esto era así porque a los 2,7 m que medían de profundidad las estancias citadas del primer y segundo piso, había que añadirle 1,05 m que medía el corredor que daba servicio a todas estas estancias y circundaba el edificio

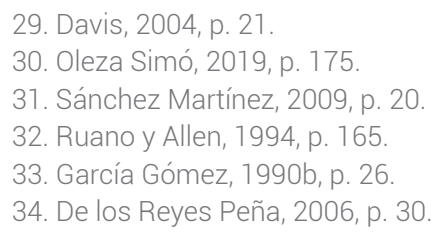


en ambas alturas, ya que dicho pasillo no llegaba a los vestuarios. Se sabe que de largo tenían 21,7 m, porque los vestuarios se situaron detrás de la pared donde estaba el tablado, frente al testero de la casa de comedias, y ocupaba todo el ancho del edificio teatral. Realmente todo el ancho de la planta del corral de comedias (18,37 m) más 3,34 m que medía un acceso al teatro, que se situó en esa parte del edificio, para las mujeres y los comediantes. Esta entrada se situó cerca de un postigo del Hospital de Nuestra Señora Santa Ana, en la calle Bodegones. A través de distintas escaleras se subía a la cazuela y a los vestuarios. La citada pared donde se ubicaron los vestuarios también se utilizaba para apariencias y tramoyas, el documento 1 cita literalmente: «tramoyas altas y bajas». Aunque en los documentos no se cite nada más sobre las tramoyas, se puede pensar que para que las hubiese altas y bajas, en cada vestuario (tanto del primer piso como del segundo), habría un balcón o puerta que daría al patio del teatro justo encima del tablado. En dichos huecos se instalarían decorados, lienzos y atrezo, además de utilizarse como espacios para la representación teatral. Incluso los mismos vestuarios servirían de almacén de todo esto, como ocurría en muchos otros corrales de comedias, como por ejemplo el de Córdoba ${ }^{35}$. Asimismo, -la memoria constructiva sí lo explicita- en dicha pared se diseñaron salidas y entradas que conectaban los vestuarios de ambos cuerpos con el tablado, con el fin de que durante la representación los actores y actrices pudieran hacer entradas y salidas de escena. Dicho tablado fue construido de madera y tenía unas dimensiones de 9,185 m de largo y 4,175 de ancho. Con sus $38,347 \mathrm{~m} 2$ pasaba por ser un gran escenario donde podían representar cómodamente los actores y las actrices. Se trató de un tablado que no desmerecía respecto a los de otros teatros barrocos españoles, ya que el escenario de la Montería tenía 6,68 m de longitud por 3,06 de profundidad y el de la Olivera $7 \mathrm{~m}$ de longitud y 5,60 $\mathrm{m}$ de profundidad ${ }^{36}$. El escenario contaba también con un tejadillo que tapaba todo el tablado como protección. Para ello se creó una base de madera, sujetada con dos columnas de madera, que fue cubierta de la misma teja que la del resto del teatro. Este pequeño tejado del escenario estaba a la misma altura que el tejado de la casa de comedias, de tal manera que hacía su función de proteger básicamente de la lluvia y no dificultaba la visión de la representación de las obras de teatro (Imagen 5).

El patio de la casa de comedias de Cartagena de 1614 era una porción de $10 \mathrm{~m}$ de ancho y 6,7 de largo (67 m2). En la documentación manejada para este artículo no hay evidencias de que existieran bancos y sillas para ubicar a los espectadores en este espacio, aunque es un hecho constatado que en los patios de los teatros barrocos había asientos para el público ${ }^{37}$. En el hueco entre las paredes maestras y la fila de pilares de ladrillo ochavados se situaron gradas de bancos de madera que servían de asiento para el público, justo debajo del primer y segundo piso (Imagen 1). Dada la poca altura que había entre el suelo y el primero piso $-2,5 \mathrm{~m}$ - no debió de ser una grada de más de dos bancos donde pudo sentarse el público que acudía 
a esta parte. De tal forma que entre estos bancos y el escenario no podía interponerse público de pie en el patio, ya que impediría la visión a los que situaban debajo de los soportales.

Los accesos al teatro fueron varios. Además de la entrada ya detallada en líneas anteriores que daba acceso a los comediantes y a las mujeres de la cazuela, en el corral de comedias existió una entrada diferente, en el testero del edificio, como puerta principal, en la calle Mayor, que daba paso a un zaguán donde se distribuían el resto de los espectadores. Desde este espacio se accedía al patio de la casa de comedias donde se situaban los bancos. También había una escalera para llegar a los aposentos de los dos cuerpos superiores, incluido el balcón de la ciudad.

En resumen, Cartagena tuvo una casa de comedias que estuvo en consonancia con el resto de teatros auriseculares, sobre todo con los de su entorno geográfico más cercano. La construcción de este teatro impulsó de manera capital la representación de comedias en la ciudad y situó a Cartagena en el mapa teatral del siglo XVII. En esta ciudad actuaron compañías tales como la de Damián Arias en 163038, Francisco Mudarra en 163539, Lorenzo Hurtado en $1638^{40}$ o Ángela Barba en 168641, todas ellas compañías de título por su majestad ${ }^{42}$. La edificación de teatros en los inicios del siglo XVII provocaba una revolución social, urbana y cultural en la ciudad donde se construían. Después de todo lo explicado en estas líneas, es evidente que, a partir de 1614, Cartagena no se mantuvo al margen de dicha revolución.

\section{APÉNDICE DOCUMENTAL}

\section{DOCUMENTO 1}

Memoria constructiva de la Casa de Comedias de Cartagena, 1614

\section{AMC. CH02290. Documento 1}

Habiendo tenido noticia de que vuestra señoría [...] método y traza de la obra que este hospital de mi Señora Santa Ana de esta ciudad de vuestra señoría y yo en su nombre, se ha comenzado a fabricar. Pongo en manos de su señoría su traza y modelo para que en lo que vuestra señoría fuese servido, ponga los reparos y advertencias que para mayor firmeza y hermosura fuese servido, que así en esto concierto. En todo lo demás fío del prudente acuerdo de vuestra señoría, mi mayor acierto y para que se reconozca lo que contiene la dicha planta con la descripción de ella como mejor pueda:

\footnotetext{
38. AMC, Acta Capitular, 11/3/1630.

39. AMC, CHO2624, Documento 21.

40. AGRM, Protocolo 5302, fols. 67-76.

41. AGRM, Protocolo 960, fols. 483r-484v.

42. Ver Varey y Shergold, 1985.
} 
El largo que dicha planta del corral de comedias que es la obra de que se trata y tiene, son 23 varas y media. Y ancho 22, debajo de cuyo [...] se obra lo siguiente:

- Las dos paredes que se han de levantar son de tapias realmente de piedra crecida en correspondencia de la que hoy está levantada [...] por ser nueva y segura, ha de servir revocándola y vistiéndola de buena mezcla, como será para las nuevas que se levantaran [...] y lo alto de ellas [...].

-Adentro del dicho corral y desde las dichas paredes maestras hasta cuatro varas y media, que son 18 palmos, se forman diez y ocho pilares de ladrillo gruesos y ochavados que tendría [...] lo que baste para que el vuelo bajo desde el suelo [...] enmaderado que den 12 palmos de alto. Y sobre [...] se han de asentar unas jácenas gruesas de [...] en cuadro. Y sobre ellas tendidos hasta estar [...] en dichas paredes maestras cuartones de a 20 palmos y 18 encargo, quedando de uno a otro a media vara de claro y todos cubiertos de viga gruesa y sana. Y de dichos pilares, jácenas y primer enmaderado han de subir otros tantos pilares en forma de columnas ochavadas de madera, del mismo grueso que las dichas jácenas, quedando este segundo cuerpo y primero de aposentos con 10 palmos de vuelo. Y los cuartones correspondientes a los primeros y cubiertos con dichas ripias en la misma conformidad prosigue con otro cuerpo que es [...] y segundo de aposentos: sobre el cual se forma [...]

\section{[página siguiente]}

Y todos dichos tejados serán hechos de teja [...] conformidad todo el corral en redondo.

4.- En este número se verán veinte y dos aposentos, que estos serán separados unos de otros con tabiques de ladrillo en canto y yeso, vestidos de lo mismo. Y en cada uno su puerta como demuestran. Y para mandarse [sic] por ellos, tendrán así en los altos como en los bajos, un callejón que ha de tener cinco cuartas de ancho y se comunicarán dichos callejones, todos, unos en otros de forma que todas las cuatro cuadras se puedan andar a la redonda sin envaradar dichos aposentos. Los dichos aposentos que quedan de 8 pies de ancho, 10 palmos de alto y 13 de fondo. $Y$ para que estos miren todos al tablado, se formaron las divisiones con todo el sesgo que sea posible para que todo el dicho aposento se aproveche y todos puedan gozar de la vista a dicho tablado.

5.- Para formar el corral en la conformidad que se necesita [...] poner el balcón de vuestra señoría en la forma que el demuestra [...] lugar [...], todo a la elección de vuestra señoría y como mejor le parezca y fuese servido así en sitio como en todo lo demás [...] Muestra que se tiene los mismos 10 palmos de alto que los demás aposentos, y los dichos 13 palmos de fondo. Y de largo [...] tiene 25 palmos que son seis varas y cuarto. Todo el dicho [...] corral está para el servicio de vuestra señoría.

6.- Lo que muestra este número es la cazuela para las mujeres que coge toda la fachada que será toda compuesta de gradas de madera formadas de ripias seguras y de poco peso. 
7.- Este número manifiesta los tejados de que tengo hecha relación.

8.- Este número demuestra el vestuario que se compone de los [...] cuerpos alto y bajo correspondientes a los de los aposentos, que ambos sirven de vestuario alto y bajo. Salidas y entradas al tablado. $Y$ tramoyas altas y bajas. $Y$ uno y otro cuarto sin comunicación a los demás, porque estos sirvan solo para el ministerio que se aplican. Que así mismo tiene de fondo 18 palmos y el largo de 26 varas, porque [...] quedan correspondientes a las 22 de ancho [...] quedan para puerta y escalera de mujeres como se [...]

\section{[página siguiente]}

9.- Lo que representa este número [...] de Señora Santa Ana [...] rejilla [...] que hoy se mira [...] ha de abrir en la [...] y de en postigo [...] para la entrada de las dichas mujeres y comediantes [...] y en esta parte que va [...] 6 varas de lo que sea necesario [...] formar caliza que sirva a todos los dichos aposentos y cazuela.

10.- En este número se muestra el tablado que según la traza tiene de largo 11 varas. Y de ancho, que es el vuelo que deja fuera del vestuario, más de 5 varas. Y en caso que sea necesario más se le darán. Si bien el de Murcia no tiene más de cuatro varas y media. Y para cubrir dicho tablado y defenderlo de los temporales, se levantan dos columnas de jácenas enteras todas estas; lo necesario para su desahogo y vista de todo el dicho corral. Y sobre ellas se ha de formar el enmaderado que lo sea suficiente. Y tejarle en la conformidad que [...] y que venga en igual con los demás, cayendo las aguas dentro del dicho corral, si bien con la ferralidad que por con [...] vengan juntas al desahogo de la calle sin que [...] a los de abajo. Y aunque en la traza [...] tejado [...] de el otro, no ha de ser así, sino como está dicho ha de venir del primero [...] púsose así para poder manifestar la obra en cuadro y que mejor se perciba.

11.- El patio que queda descubierto sin lo que queda debajo de los aposentos es de ancho 12 varas y [...] en frente por lo menos de 8 varas, que todo [...] debajo de los portales sirve para bancos en la forma acostumbrada. Esta es la relación de todo el compuesto de la dicha obra. Quedo debajo de la censura y acuerdo de vuestra señoría. 


\section{IMÁGENES}

Imagen 1

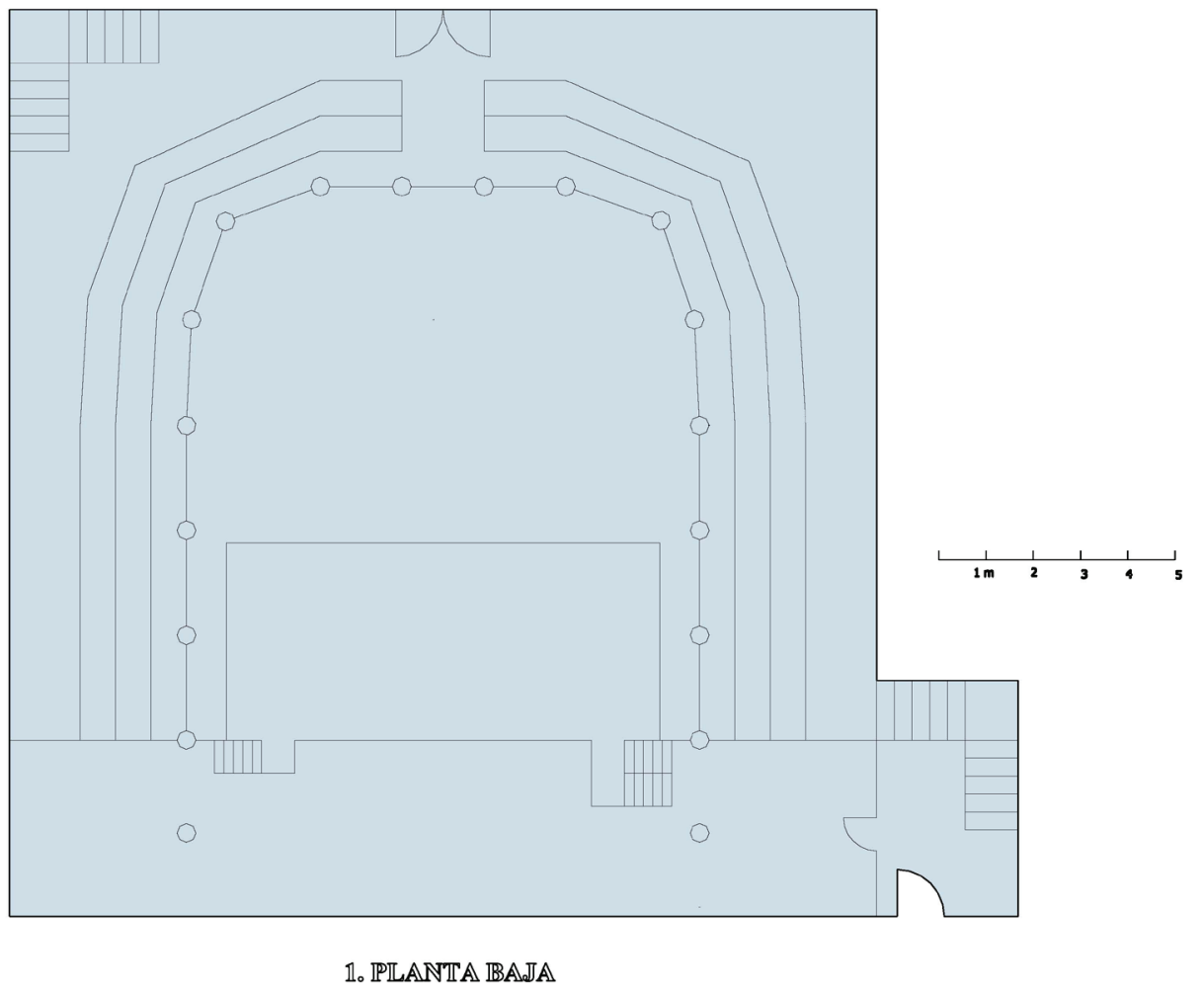


Imagen 2

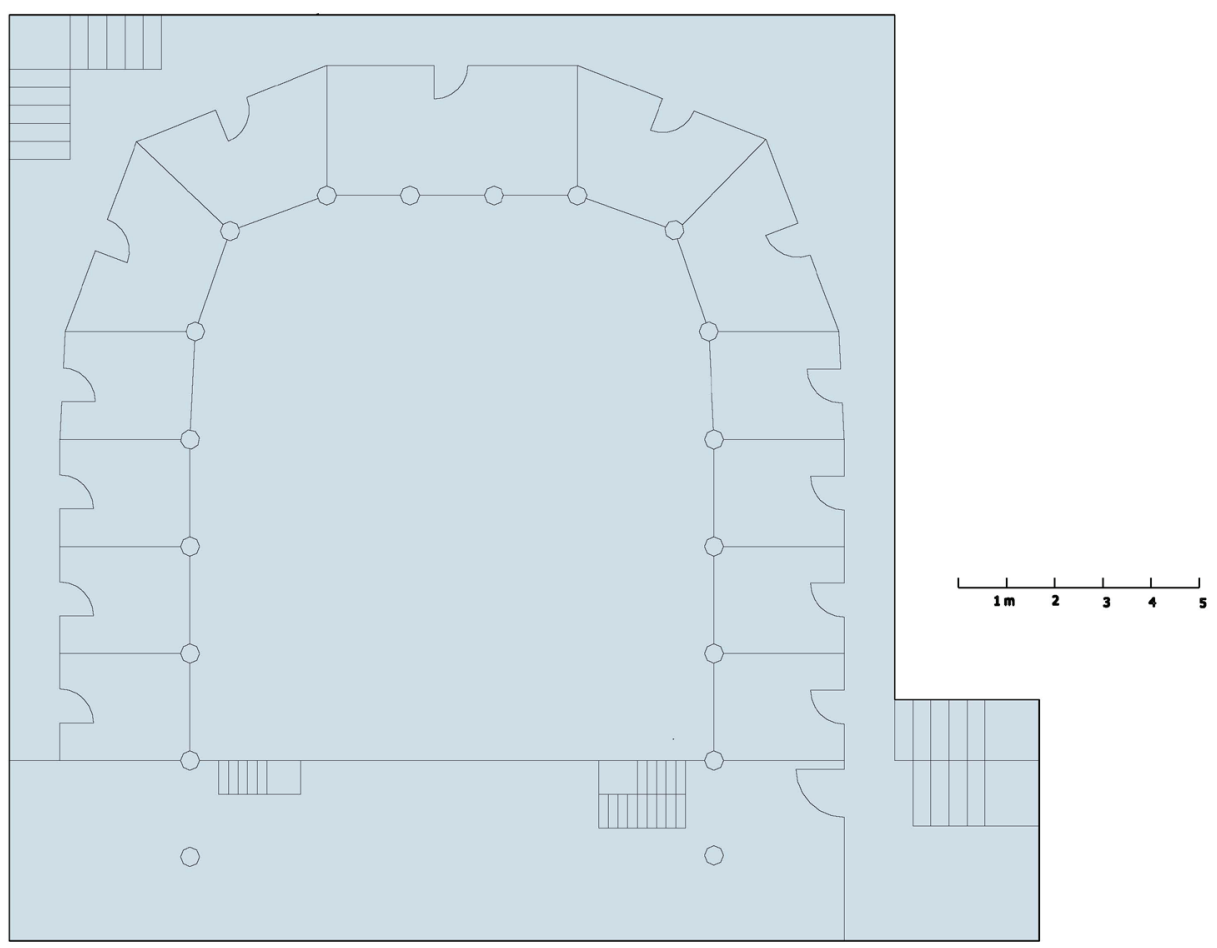

2. PLANTA IPRIMIIERA 
Imagen 3

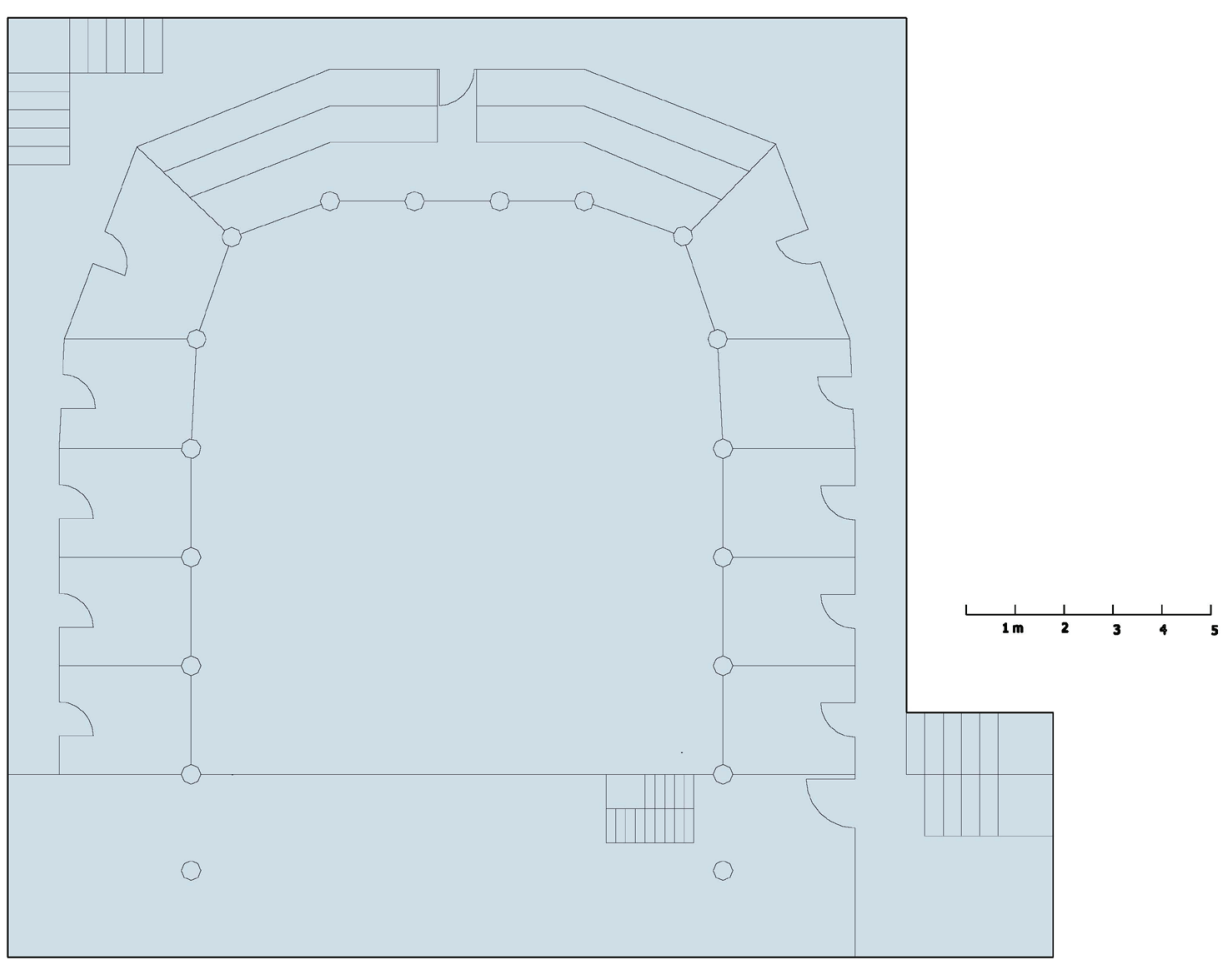

3. RLANTA SIEGUNIDA 
Imagen 4

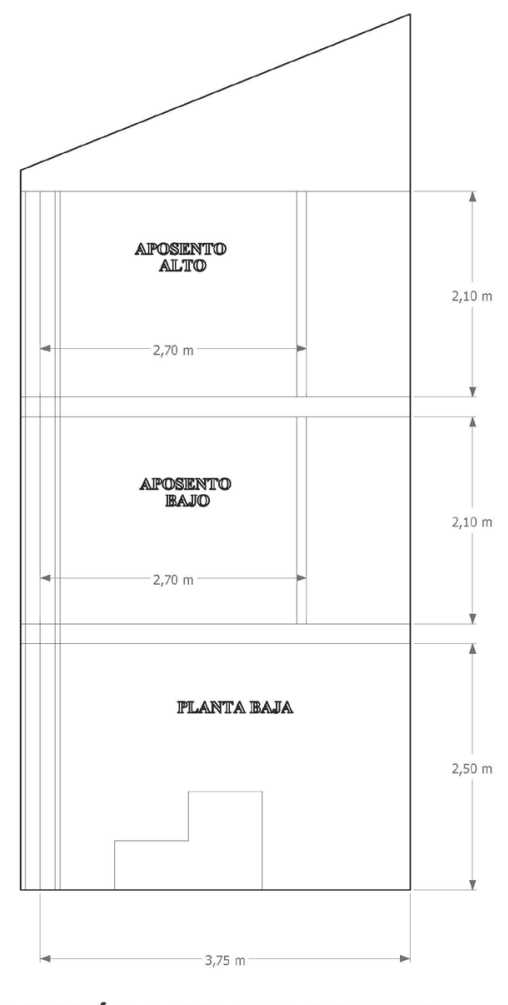

4. SECCION TRRANSVIERSAIL APOSIENTIOS 
Imagen 5

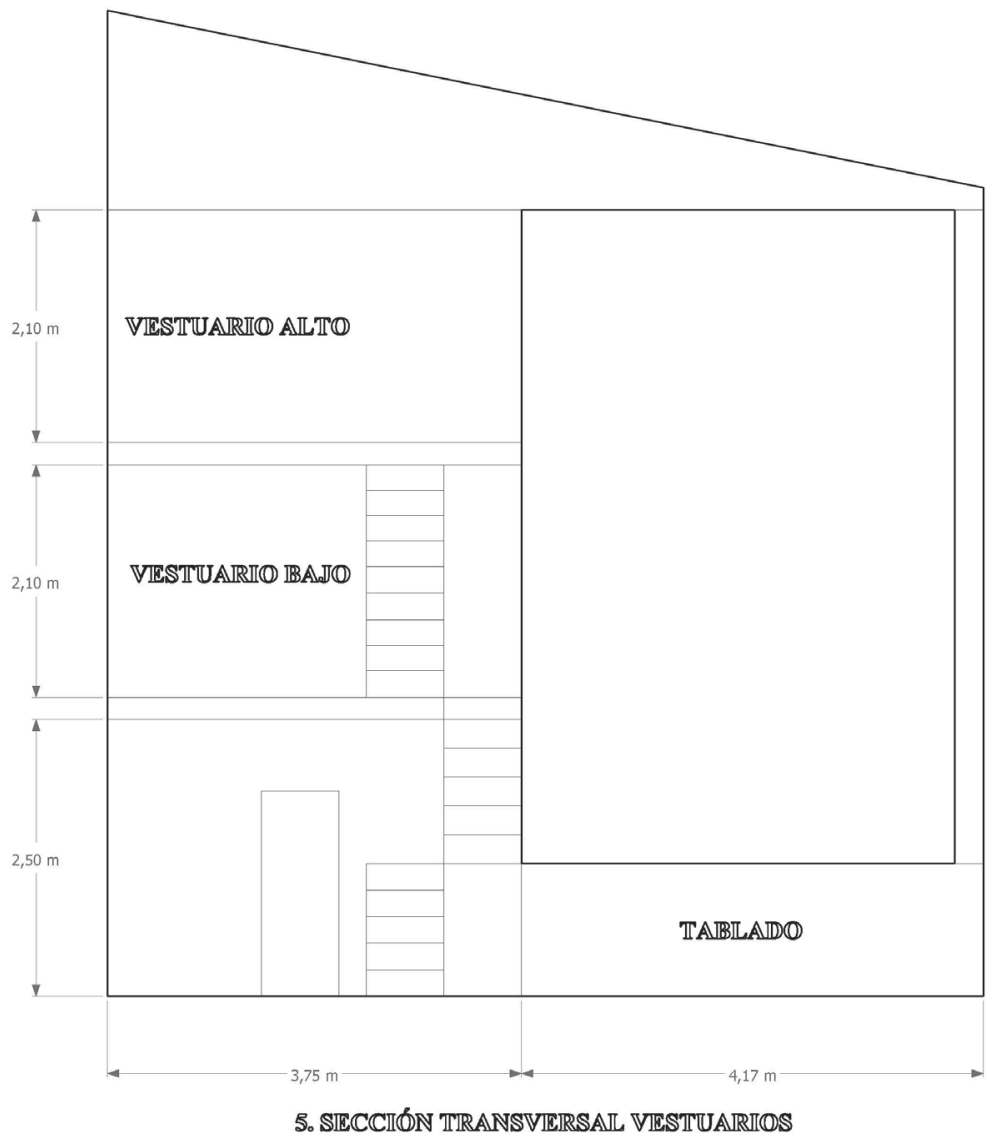

HIPOGRIFO, 9.1, 2021 (pp. 1285-1303) 
Imagen 6

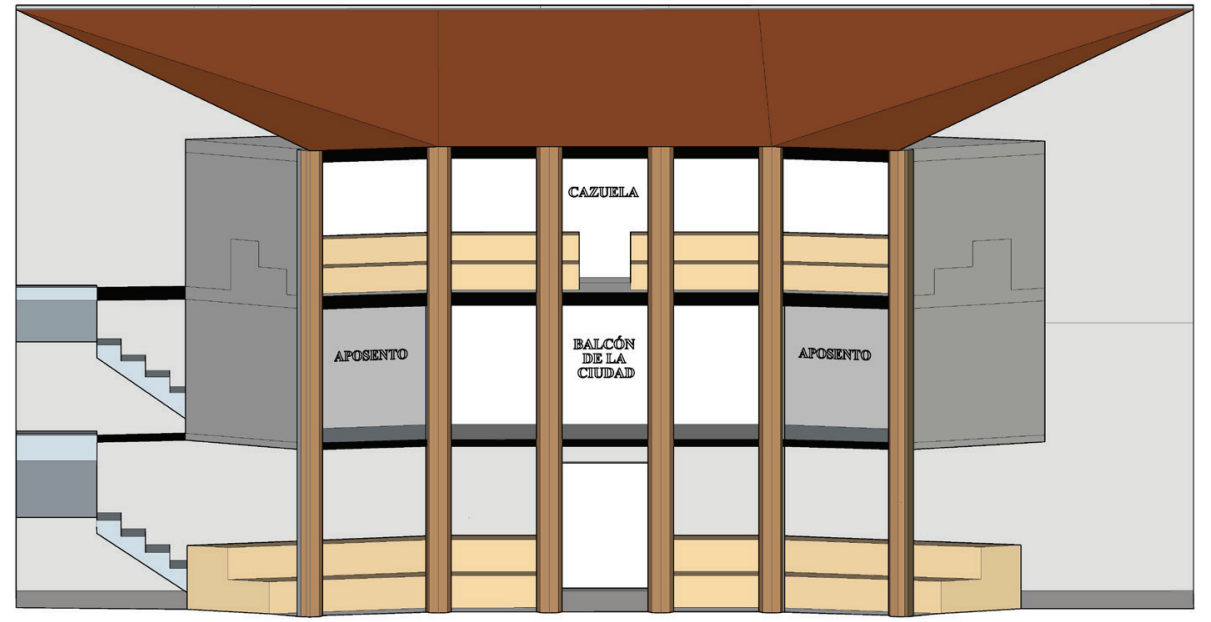

6. CAZUUELA Y BALCCONN DE LA CIUUDAD 


\section{BiBLIOgRAFÍA}

Andrés Sarasa, José Luis, Cartagena, estudio de geografía urbana, Murcia, Universidad de Murcia, 1981.

Basas Fernández, Manuel, Antiguos sistemas de pesos y medidas, Bilbao, Caja de Ahorros Vizcaína, 1980.

Bolaños Donoso, Piedad, «Acerca del corral de las Atarazanas», Edad de Oro, 16, 1997, pp. 67-87.

Davis, Charles, Los aposentos del Corral de la Cruz. 1581-1823, Londres, Tamesis Books, 2004.

Davis, Charles, y Varey, John Earl, Los Corrales de Comedias y los Hospitales de Madrid: 1574-1615. Estudio y documentos, Londres, Tamesis Books, 1997.

Ferrándiz Araujo, Carlos, «Los hospitales renacentistas de Murcia y Cartagena», Murgetana, 115, 2006, pp. 57-63.

Florit Durán, Francisco, y Sánchez Martínez, Rafael, «Teatro barroco en Murcia: el corral de comedias del Toro (1609-1633)», en En torno al Barroco: miradas múltiples, ed. Concepción de la Peña, Murcia, Universidad de Murcia, 2007, pp. 29-42.

García Gómez, Ángel María, Casa de las Comedias de Córdoba: 1602-1694, Londres, Tamesis Books, 1990a.

García Gómez, Ángel María, «Casa de las Comedias de Córdoba (1602-1694): contribución a su historia documental», Criticón, 50, 1990b, pp. 23-40.

García Lorenzo, Luciano, y Varey, John Earl, Teatros y vida teatral en el Siglo de Oro a través de las fuentes documentales, Londres, Tamesis Books, 1992.

Montojo Montojo, Vicente, El Siglo de Oro en Cartagena (1480-1640): evolución económica y social de una ciudad portuaria del Sureste español y su comarca, Cartagena, Ayuntamiento de Cartagena, 1993.

Oleza Simó, Joan, «La Montería y la Olivera: dos teatros en un contexto de cambio cultural», Atalanta, 7, vol. 2, 2019, pp. 148-189.

Pérez Yelo, Martín, Guía de arquitectura de Cartagena. La sucesión del estilo. 15031875, Cartagena, UPTC, 2013.

Sánchez Martínez, Rafael, El teatro comercial en Murcia durante el siglo XVII (15931695): estudios y documentos, Londres, Tamesis Books, 2009.

Ruano de la Haza, Jose María, y Allen, John Jay, Los teatros comerciales del siglo XVII y la escenificación de la comedia, Madrid, Castalia, 1994. 
Reyes Peña, Mercedes de los, «El corral de la Montería en Sevilla», en El corral de comedias. Espacio escénico, espacio dramático. Actas de las XXVII Jornadas de teatro clásico de Almagro. 6, 7, 8 de julio de 2004, ed. Felipe B. Pedraza Jiménez, Rafael González Cañal y Elena E. Marcello, Cuenca, Junta de Comunidades de Castilla-La Mancha, 2006, pp. 19-60.

Tornel, Cayetano, Grandal, Alfonso, y Rivas, Ángel, Textos para la historia de Cartagena: siglos XVI-XX, Cartagena, Ayuntamiento de Cartagena, 1985.

Varey, John Earl, y Shergold, Norman David, Genealogía, origen y noticias de los comediantes en España, London, Tamesis books, 1985.

Velasco Hernández, Francisco, «El auge económico de Cartagena y la revitalización del sureste español en los siglos XVI y XVII», Hispania, 220, 2005, pp. 485-514.

Vitruvio, Los diez libros de la arquitectura, Barcelona, Iberia, 1955. 